\title{
Performance evaluation of two models in the reactive routing protocol in manets
}

\author{
MuthannaJaafar Abbas ${ }^{1}$, Haider Mohammed Turki Alhilfi ${ }^{2}$, Tole Sutikno ${ }^{3}$ \\ ${ }^{1}$ Department Departement of Electrochemical Engineering, Babylon University, Hillah, Iraq \\ ${ }^{2}$ Ministry of Education/General Directorate for Vocational Education, Iraq \\ ${ }^{3}$ Department of Electrical Engineering, Universitas Ahmad Dahlan, Yogyakarta, Indonesia \\ ${ }^{3}$ Embedded System and Power Electronics Research Group (ESPERG), Yogyakarta, Indonesia
}

\section{Article Info}

\section{Article history:}

Received Feb 1, 2020

Revised Jun 26, 2020

Accepted Aug 8, 2020

Keywords:

Manet

Odav

Packet delivery

Tora

ABSTRACT

Due to the need for the multicast connection required by multimedia applications such as video conferencing and natural disaster management, it was necessary to use a set of portable and connected wireless peripheral devices without the need for infrastructure and without a central router, by use wireless network as "a mobile ad hoc network (MANET)". Despite the difficulties facing this technology in the process of effective guidance and the expansion of the use of such networks, in this type of network because of its applications in the fields of civil and military systems that do not need an infrastructure for the network to provide communication, the researchers specialized in this field have improved the current routing protocols and design new protocols that are appropriate to the challenges that Routing protocols face due to continuous change In network topology over time. In this paper we improved the current routing protocols and design new protocols that are appropriate to the challenges that routing protocols face due to continuous change In network topology over time. The NS2 simulation environment was used for the purpose of a comprehensive evaluation of the performance of the TORA and AODV routing protocols By using properties of packet delivery fraction and end-to-end delay was calculated.
\end{abstract}

This is an open access article under the CC BY-SA license.

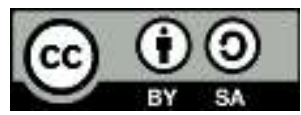

\section{Corresponding Author:}

Haider Mohammed Turki Alhilfi

Ministry of Education/General Directorate for Vocational Education, Iraq

Email: haider791977@gmail.com

\section{INTRODUCTION}

The Usually, this network consists of a group of mobile nodes wirelessly connected in a selfconfigured network without a stable infrastructure. The network structure of this technique is constantly changing due to the free random movement of the nodes. Each node is itself directed during traffic to the other group of nodes that make up the network. When a node is separated from the network domain, the network searches for the shortest and most secure way through the routing protocol to define the nodes, as well as the complete communication of the network is not disrupted by the failure of one node within the network [1-3]. There are many multicast routing protocols (topology based) to support communication through the many packets that the sender sends from receivers to a unique address [4-6].

Dissemination of information from a transmitter to all multicast receivers is supported by MANET multicast routing protocols. These protocols are divided into several types of multicast routing as meshbased, tree-based, and hybrid [7-9]. There are many routing protocols that automatically regulate the network 
for the purpose of arriving packets sent to their destination while traveling from one location to another and effectively, the classification of these protocols depends on the paths of the nodes that discover from the nodes themselves [10-13]. Reactive routing protocols, a protocol that starts on demand and is called a source routing protocol. Where the route is discovered when needed, and upon request the route is discovered. Path detection begins by the source node, which specifies its path through the available path, and which it detects from the source to the destination [14-16]. In the on-demand routing protocol there are two main components: route discovery: upon request, the path is detected by the source node, instead of having a list of all paths and for each destination being preserved. The packet is sent to the destination node from the source node after the link is set, in other words the network is dumping routing request packets from In order to discover the desired path.

Route Maintenance: is the correction process that is made through periodic signals, because a break in the link leads to a path failure, because the network topology changes frequently due to the mobility of the nodes [7]. The example of this protocol are the ad hoc on-demand distance vector routing (AODV), temporary ordered routing protocol (TORA), signal stability based adaptive routing protocol (SSA), dynamic source routing (DSR), associativity based routing (ABR) [17-19]. Proactive Routing Protocols Proactive routing protocols based on general structure information saved in the form of routing tables updated frequently and periodically with the change in network topology and stored in each node, and wired network routing protocols are an extension of them. It is known that large networks do not fit these protocols because they need to keep node entries in the routing table and for each node. The number of routing tables varies from protocol to protocol [20-22]. The example of this protocol is dynamic destination sequenced distance vector routing protocol (DSDV), cluster gateway switch routing protocol (CGSR), wireless routing protocol (WRP) [23-26].

Hybrid routing protocols: proactive protocols have less latency and large overhead on the contrary from reactive protocols have more latency and less overhead. To overcome the shortcomings of both interactive and proactive routing protocols, a hybrid protocol was introduced, which is a combination of both reactive and proactive routing protocols. It uses a table maintenance mechanism and routes discovery mechanism to avoid overhead and latency problems in the network. This protocol is suitable for networks with large numbers of nodes. This large network is divided into a group of a zone where a reaction approach within the zone is used to implement routing in. the example of this protocol is zone routing protocol (ZRP) and sharp hybrid adaptive routing protocol (SHARP). The main contribution of this paper as follow:

a) Improving the current routing protocols and design new protocols that are appropriate to the challenges that routing protocols face due to continuous change in network topology over time.

b) The NS 2 simulation environment was used for the purpose of a comprehensive evaluation of the performance of the TORA and AODV routing protocols By using properties of packet delivery fraction and end-to-end delay was calculated.

\section{OVERVIEW OF AODV AND TORA}

In this paper, we will choose two routing protocols, AODV and TORA taking into account the nature of each of the advantages and disadvantages.

\subsection{Ad hoc on-demand distance vector routing (AODV)}

AODV is characterized by its ability to diversify unicast and multicast, it is noted that the source node sends over the network the RREQ route request packet for the purpose of directing a specific route to a destination that does not have a route [27-30]. After receiving the package containing the destination sequence number by the targeted nodes, it updates its source information as well as the current sequence number, IP address, and broadcast ID of the source node, the response is made by the destination node or that has a path to a destination on the RREP path with a corresponding sequence number (equal to or greater than the number in the RREQ). Packet data is forwarded by the source node to the destination after receiving the RREP. When there are inaccessible destinations, the Initial node informs the source node of unreachable destinations by posting an error message in the path RERR, Thus the source node is optimized for route detection [31].

\subsection{Temporary ordered routing algorithm (TORA)}

A routing protocol used for high-traffic (multihop wireless) networks, based on the principle of link reversal for highly dynamic mobile, distributed highly adaptable routing algorithm. Looking at multiple paths from the source node to the target or destination node [32]. in this protocol, near the occurrence of a topological change, the control messages are localized to a very small set of nodes, and orientation 
information for the adjacent node is preserved by the node itself, There are three primary functions to this protocol by using three messages to do this task:

a) "QRY message" creating a route.

b) "UDP message" creating and maintaining routes.

c) "CLR message" erasing a route.

\section{SIMULATION AND RESULTS}

The network simulator (Ns-2) was used for simulation for AODV and TORA protocals, and simulation time $400 \mathrm{sec}$ and transmission rang $300 \mathrm{~m}$, bandwidth $2 \mathrm{Mbps}$, the source and destination node randomly and separately 'random waypoint model' Dimension of used field $1000 \mathrm{~m} \times 1000 \mathrm{~m}$ with 80 nodes, In this simulation, several different network scenarios will be generated, including different numbers of nodes and different pause time. For each moving node, a destination is randomly chosen from its random location. There is a pause time that the destination node takes on arrival before another random destination is chosen. Therefore, there will be changes in the network topology on an ongoing basis as a result of the repeated scenario of movement, as we explained above during the simulation. The results of the comparison between the two protocols (AODV and TORA) are represented by the graphs shown in the figures that we obtained through simulation.

\section{PERFORMANCE ANALYSIS}

\subsection{Throughput, packet delivery fraction}

Throughput it is the Data and information transmitted in relation to a specific time and expressed in (Kbps), consequently, the Figures 1, 2, 3 resulting from the use of different traffic sources shows a comparison between the two protocols on the basis of PDF, From the figures, we note that the increase in mobility leads to a decrease in Throughput or decrease (packet drop). Because of the time, it takes to discover the path from the source to the destination, which is proportional to the distance between the source and the destination, a large number of packets will drops. In our simulation, it is noted that AODV performance in general is better, It is also noted that TORA performance has a lower throughput while it is better in higher mobility. Compared to other protocols, TORA is completely affected when routing packets are lost. There is a possibility to improve the performance of both AODV and TORA by buffering of data packets. Figures 1-3 shows us the relationship between packet delivery fraction and pause time when using 80 -node model with a different number of sources for each figure, Table 1 showing the values of the packet delivery ratio.

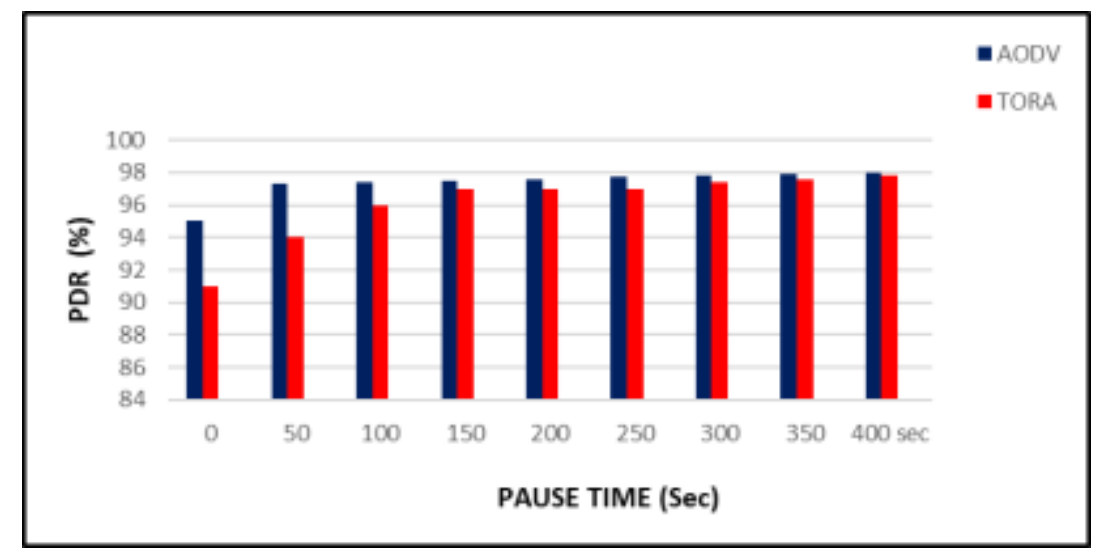

Figure 1. 15 sources

Table 1. Showing the values of the packet delivery ratio (\%) at pause time $150 \mathrm{sec}$ for both protocol for deferent sources

\begin{tabular}{|c|c|c|c|}
\hline & 15 sources & 30 sources & 80 sources \\
\hline AODV & 97.5 & 93 & 87 \\
\hline TORA & 97 & 89.5 & 80.4 \\
\hline
\end{tabular}




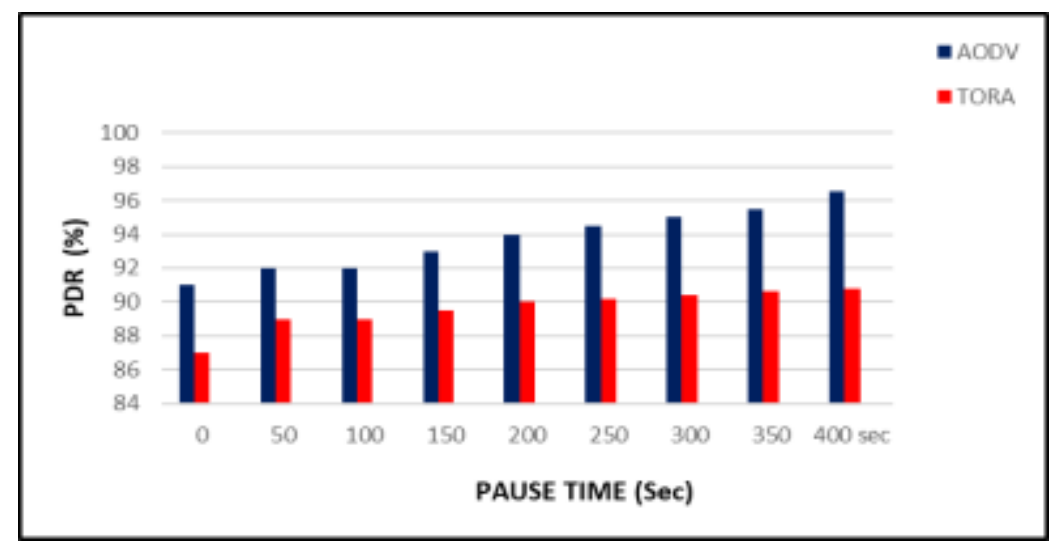

Figure 2. 30 sources

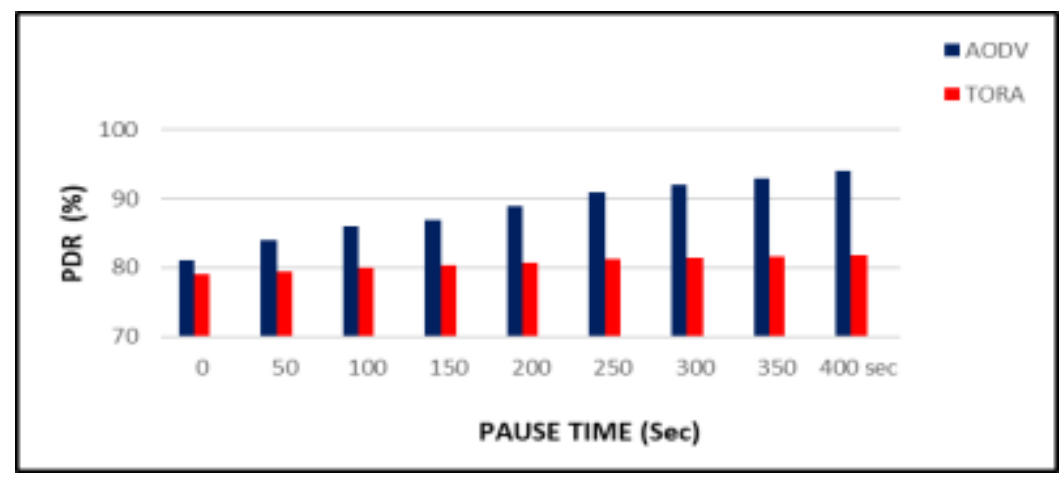

Figure 3. 80 sources

\subsection{End to end delay}

Note through the Figures 4, 5, 6, shows us the relationship between end to end delay and pause time when using 80-node model with a different number of sources for each figure. Table 2 showing the values of the end to end delay, also from the figures below, it is clear that the increase in the number of nodes waiting in the interface queue is proportional to the increase in the average delay of the packet, delay time is an inevitable consequence of path detection by routing protocols to the destination. AODV performed better than TORA, for the following reasons:

a) Due to loss of distance information with progress, The TORA has the worst characteristics of delay.

b) There is a clear slowness of TORA to construction of route, Thus, the process of identifying new routes leads to further delay.

with lower mobility in (large networks), TORA is showing better performance.

In general, searching for the best is the purpose of a performance evaluation comparison in simulation experience between AODV and TORA routing protocols, TORA has a high throughput compared to AODV and also has better performance when mobility at a high speed.

Table 2. Showing the values of the end to end delay (\%) at pause time $150 \mathrm{Sec}$ for both protocol for deferent sources

\begin{tabular}{cccc}
\hline & 15 sources & 30 sources & 80 sources \\
\hline AODV & 17.5 & 16 & 16 \\
TORA & 12 & 13.8 & 14 \\
\hline
\end{tabular}




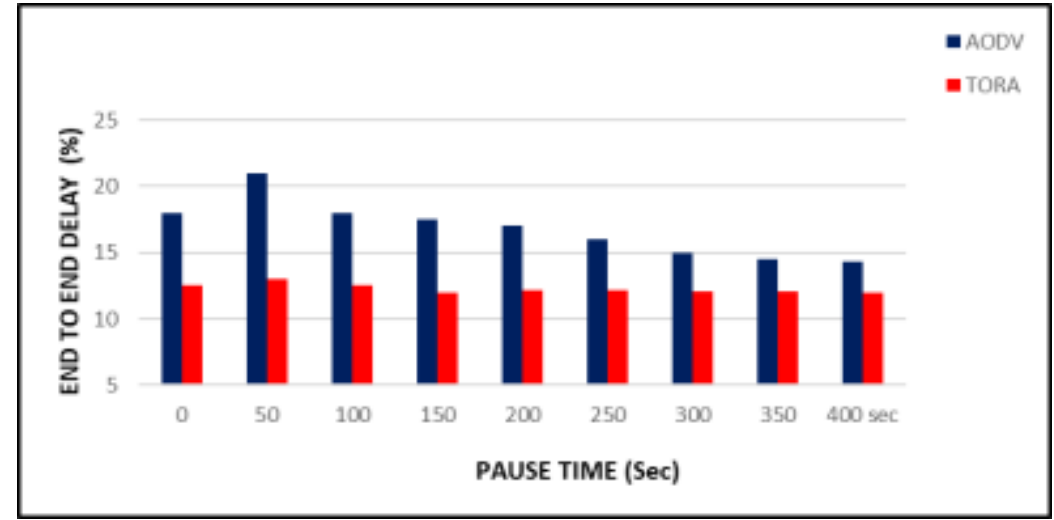

Figure 4. 15 sources

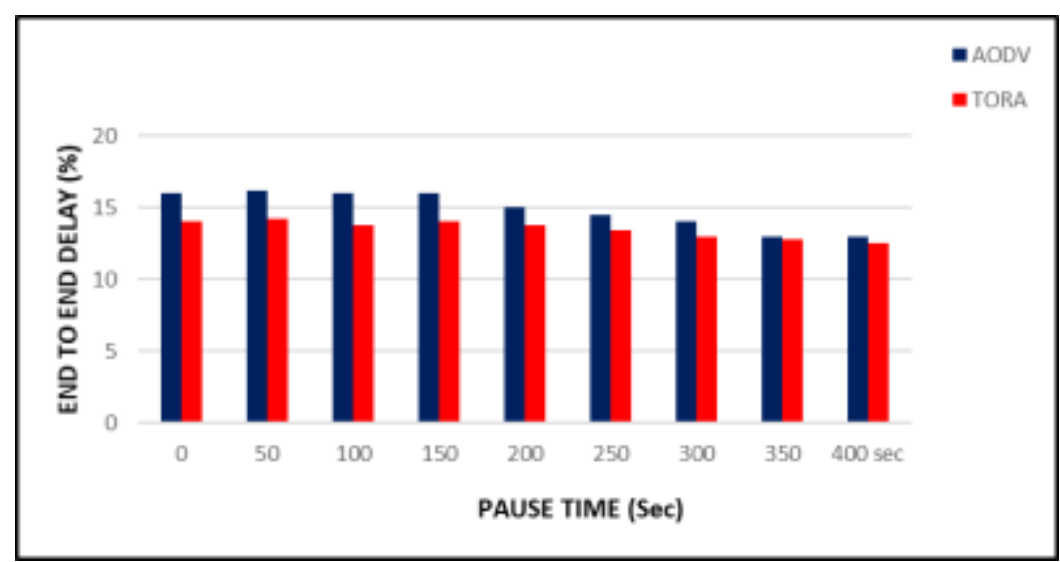

Figure 5. 30 sources

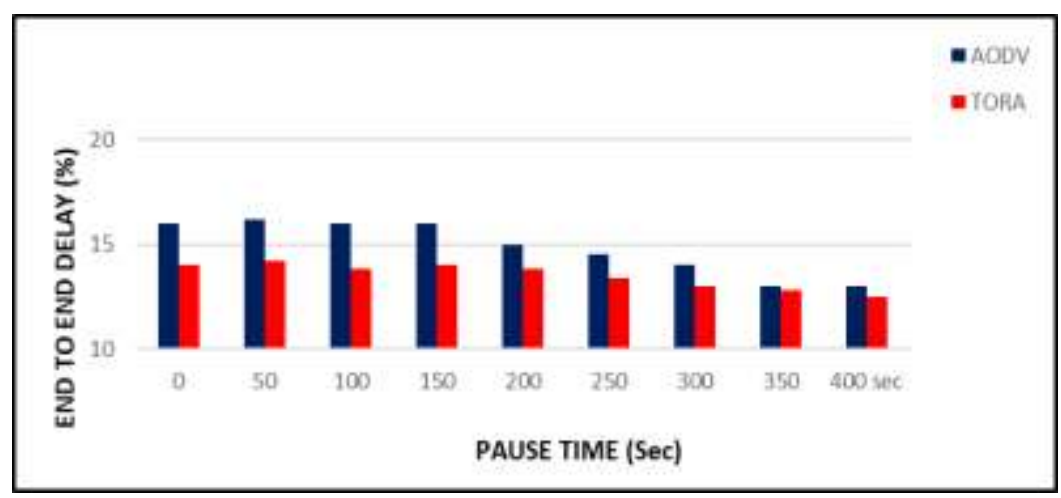

Figure 6. 80 sources

\section{CONCLUSION}

Recently there has been a lot of research in this special type of network because of its applications in the fields of civil and military systems that do not need an infrastructure for the network to provide communication, the researchers specialized in this field have improved the current routing protocols and design new protocols that are appropriate to the challenges that routing protocols face due to continuous change In network topology over time. The NS 2 simulation environment was used for the purpose of a comprehensive evaluation of the performance of the TORA and AODV routing protocols by using properties of packet delivery fraction and end-to-end delay in this simulation. 
The following has been concluded: the increase in the mean end-to-end delay is proportional to the increase in the nodes intensity, as well as decrease has occurred in the mean end-to-end delay due to the increase in the pause time, meantime for loop detection will increase due to the increase in the number of nodes. AODV compared to TORA, is the best overall performance. TORA suitable for networks that have more nodes for multicasting and multiple routes. In future it is possible in the future to conduct a more comprehensive simulation process using modern and customized protocols to obtain a better performance analysis and a broader scope.

\section{REFERENCES}

[1] L. J. García Villalba, J. García Matesanz, A. L. Sandoval Orozco, and J. D. Márquez Díaz, “Auto-Configuration Protocols in Mobile Ad Hoc Networks," Sensors Journal, vol. 11, no. 4, pp. 3652-3666, 2011.

[2] Shaveta Jain and Kushagra. Agrawal, "A Survey on Multicast Routing Protocols for Mobile Ad Hoc Networks," International Journal of Computer Applications, vol. 96, no. 14, pp. 975-8887, 2014.

[3] Lee, S.J., Gerla, M. and Chiang, C.C., "On-demand multicast routing protocol in multi hop wireless mobile networks," Mobile Networks and Applications Journal, vol. 7, pp. 441-453, 2002.

[4] S. John Justin Thangaraj, Rengarajan A and Selvanayaki S, "Comprehensive Learning on Characteristics, Applications, Issues and Limitations of Manets," International Journal of Innovative Technology and Exploring Engineering (IJITEE), Vol. 8, No. 9S2, pp. 311-314, July 2019.

[5] Sandeep Kumar and Suresh Kumar, "Characteristics, Challenges, Application, Routing Protocol and Security AttacksCharacteristics, Challenges, Application, Routing Protocol and Security Attacks," International Journal of $R \& D$ in Engineering, Science and Management, vol. 2, no. 5, pp. 266-274, July 2015.

[6] Lucia Keleadile Ketshabetswe, Adamu Murtala Zungeru, Mmoloki Mangwala, Joseph M. Chuma, and Boyce Sigweni, "Communication protocols for wireless sensor networks: A survey and comparison," Heliyon Journal, vol. 5, no. 5, May 2019.

[7] Roswan Ismail, Che Zalina Zulkifli and Khairulanuar Samsudin "Routing protocols for mobile Ad-Hoc network: A qualitative comparative analysis,” Jurnal Teknologi (Sciences \& Engineering), vol. 78, no. 8, pp.1-10, 15 July 2016.

[8] V. C. Giruka, M. Singhal and S. P. Yarravarapu, "A path compression technique for on-demand ad-hoc routing protocols," 2004 IEEE International Conference on Mobile Ad-hoc and Sensor Systems (IEEE Cat. No.04EX975), Fort Lauderdale, FL, USA, pp. 144-153, 2004. doi: 10.1109/MAHSS.2004.1392092.

[9] Shyamrao V Gumaste, Dr. M. U. Kharat, Dr. V. M. Thakare and V. T. Kharat, "Routing Algorithm: An Overview," International Journal of Innovations in Engineering and Management, vol. 2, no. 1, pp. 61-73, 2013.

[10] Muthanna Jaafar Abbas and Abeer Abd Al Hameed Mahmood, "Efficiency and effectiveness video on demand over worldwide interoperability for microwave access," International Journal of Electrical and Computer Engineering (IJECE), vol. 9, no. 3, pp. 1919-1923, June 2019.

[11] Sumon Kumar Debnath, Foez Ahmed, and Nayeema Islam, "Performance Evaluation of Unicast and Broadcast Mobile Ad-hoc Networks Routing Protocols," (IJCSIS) International Journal of Computer Science and Information Security, vol. 7, no. 1, pp. 40-46, 2010.

[12] Rajendiran .M and Srivatsa .S .K., Dr. M. U. Kharat, Dr. V. M. Thakare and V. T. Kharat, "On-Demand Multicasting in Ad-hoc Networks: Performance Evaluation of AODV, ODMRP and FSR," IJCSI International Journal of Computer Science Issues, vol. 8, no. 3, pp. 478-482, May 2011.

[13] Haider Mohammed Turki AL-Hilfi, Rajeev Paulus, A. K. Jaiswal and A. Ashok, "Performance Comparison of a Reactive and Hierarchical Routing Protocol In 802.16e Using Qualnet 6.1," International Journal of Current Engineering and Technology, vol. 4, no. 3, pp. 1745-1748, June 2014.

[14] Haider Mohammed Turki AL-Hilfi, Bassam Abdulmunem Salih and Ion Marghescu, "Design of secured WLAN by using "packet filtering firewall," IEEE Xplore Digital Library, Conference, Chennai, India, 22 February 2018.

[15] Ashek Raihan Mahmud, Mahbubur Rahman and Sipon Miah, "Performance Analysis Of Routing Protocols For Cbr Traffic In Mobile Ad-Hoc Networks,” Journal of information, vol. 9, no. 1, pp. 1-9, 2016.

[16] R. A. Hasan, M. A. Mohammed, N. Țăpuş, and O. A. Hammood, "A comprehensive study: Ant Colony Optimization (ACO) for facility layout problem," in 2017 16th RoEduNet Conference: Networking in Education and Research (RoEduNet), pp. 1-8, 2017.

[17] R. A. Hasan and M. N. Mohammed, "A krill herd behaviour inspired load balancing of tasks in cloud computing," Studies in Informatics and Control, vol. 26, pp. 413-424, 2017.

[18] Z. F. Hussain, H. R. Ibraheem, M. Alsajri, A. Hussein Ali, M. A. Ismail, S. Kasim, et al., "A new model for iris data set classification based on linear support vector machine parameter's optimization," International Journal of Electrical \& Computer Engineering, vol. 10, no. 1, pp. 1079-1084, 2020.

[19] M. A. Mohammed and R. A. Hasan, "Particle swarm optimization for facility layout problems FLP-A comprehensive study," in 2017 13th IEEE International Conference on Intelligent Computer Communication and Processing (ICCP), pp. 93-99, 2017.

[20] M. A. Mohammed, R. A. Hasan, M. A. Ahmed, N. Tapus, M. A. Shanan, M. K. Khaleel, et al., "A Focal load balancer based algorithm for task assignment in cloud environment," in 2018 10th International Conference on Electronics, Computers and Artificial Intelligence (ECAI), 2018.

[21] M. A. Mohammed, A. A. Kamil, R. A. Hasan, and N. Tapus, "An Effective Context Sensitive Offloading System for Mobile Cloud Environments using Support Value-based Classification," Scalable Computing: Practice and Experience, vol. 20, pp. 687-698, 2019. 
[22] M. A. Mohammed, I. A. Mohammed, R. A. Hasan, N. Ţăpuş, A. H. Ali, and O. A. Hammood, "Green Energy Sources: Issues and Challenges," in 2019 18th RoEduNet Conference: Networking in Education and Research (RoEduNet), pp. 1-8, 2019.

[23] M. A. Mohammed, Z. H. Salih, N. Ţăpuş, and R. A. K. Hasan, "Security and accountability for sharing the data stored in the cloud," in 2016 15th RoEduNet Conference: Networking in Education and Research, pp. 1-5, 2016.

[24] M. A. Mohammed and N. TĂPUŞ, “A Novel Approach of Reducing Energy Consumption by Utilizing Enthalpy in Mobile Cloud Computing," Studies in Informatics and Control, vol. 26, pp. 425-434, 2017.

[25] N. Q. Mohammed, M. S. Ahmed, M. A. Mohammed, O. A. Hammood, H. A. N. Alshara, and A. A. Kamil, "Comparative Analysis between Solar and Wind Turbine Energy Sources in IoT Based on Economical and Efficiency Considerations," in 2019 22nd International Conference on Control Systems and Computer Science (CSCS), pp. 448-452, 2019.

[26] M. A. A. Royida A. Ibrahem Alhayali, Yasmin Makki Mohialden, Ahmed H. Ali, "Efficient method for breast cancer classification based on ensemble hoffeding tree and naïve Bayes," Indonesian Journal of Electrical Engineering and Computer Science, vol. 18, pp. 1074-1080, 2020.

[27] Z. H. Salih, G. T. Hasan, and M. A. Mohammed, "Investigate and analyze the levels of electromagnetic radiations emitted from underground power cables extended in modern cities," in 2017 9th International Conference on Electronics, Computers and Artificial Intelligence (ECAI), 2017.

[28] Z. H. Salih, G. T. Hasan, M. A. Mohammed, M. A. S. Klib, A. H. Ali, and R. A. Ibrahim, "Study the Effect of Integrating the Solar Energy Source on Stability of Electrical Distribution System," in 2019 22nd International Conference on Control Systems and Computer Science (CSCS), pp. 443-447, 2019.

[29] N. D. Zaki, N. Y. Hashim, Y. M. Mohialden, M. A. Mohammed, T. Sutikno, and A. H. Ali, "A real-time big data sentiment analysis for iraqi tweets using spark streaming," Bulletin of Electrical Engineering and Informatics, vol. 9, pp. 1411-1419, 2020.

[30] O. A. Hammood, M. N. M. Kahar, M. N. Mohammed, W. A. Hammood, and J. Sulaiman, "The VANET-Solution Approach for Data Packet Forwarding Improvement," Advanced Science Letters, vol. 24, pp. 7423-7427, 2018.

[31] O. A. Hammood, N. Nizam, M. Nafaa, and W. A. Hammood, "RESP: Relay Suitability-based Routing Protocol for Video Streaming in Vehicular Ad Hoc Networks," International Journal of Computers, Communications \& Control, vol. 14, 2019.

[32] R. A. Hasan, M. A. Mohammed, Z. H. Salih, M. A. B. Ameedeen, N. Ţăpuş, and M. N. Mohammed, "HSO: A Hybrid Swarm Optimization Algorithm for Reducing Energy Consumption in the Cloudlets," Telkomnika, vol. 16, pp. 2144-2154, 2018. 